\title{
Architect's and Geologist's View on the Causes of Building Failures in Nigeria
}

\author{
Amadi A. N. ${ }^{1}$, Eze C. J. ${ }^{2}$, Igwe C. O. ${ }^{3}$, Okunlola I. A. ${ }^{1} \&$ Okoye N. O. ${ }^{1}$ \\ ${ }^{1}$ Department of Geology, Federal University of Technology, Minna, Nigeria \\ ${ }^{2}$ Department of Architecture, Federal University of Technology, Minna, Nigeria \\ ${ }^{3}$ Department of Industrial and Technology Education, Federal University of Technology, Minna, Nigeria \\ Correspondence: Amadi A. N., Department of Geology, Federal University of Technology, Minna, Nigeria. Tel: \\ 234-803-772-9977. E-mail: geoama76@gmail.com
}

\author{
Received: April 10, 2012 Accepted: May 9, 2012 Online Published: May 16, 2012 \\ doi:10.5539/mas.v6n6p31 URL: http://dx.doi.org/10.5539/mas.v6n6p31
}

\begin{abstract}
The collapse of building in most cases is associated with loss of life and properties. The incessant failures of building nowadays are so enormous that it has become a serious concern to the professionals in the building industry, clients, governments, and the general public. Most of the times, the architect and engineer who are directly involved in the construction of such building are held responsible for building failures while the geologist's input is neglected. The frequent collapse of some buildings in major cities in Nigeria can be attributed to absence of a geotechnical report on the project site before, during and after the construction exercise. Studies have shown that geotechnical investigation report of a four storey residential building covering $420 \mathrm{~m}^{2}$ at No. 56 Bola Street, Ebute-Metta, Lagos, that collapsed on $26^{\text {th }}$ July, 2006 was as a result of the existence of reddish brown silty clayey material and compressible waste material like wood, plastic and nylon occurring from ground surface to about $11 \mathrm{~m}$ on which a shallow strip foundation was used. More so, on $1^{\text {st }}$ July, 2006, another 3- Storey building collapsed along Bank road, Port-Harcourt. The result of the liquid limit, plasticity index, shrinkage potential, moisture content, tri-axial stress range and coefficient of consolidation carried out on the two locations indicates that the soil have low bearing capacity. The collapsed of these buildings were attributed to under design, improper supervision, poor quality construction, poor funding, use of sub-standard construction materials and absence of geo-technical investigation and engagement of non-professionals (quacks). This paper therefore x-rays the causes of building failures in Nigeria and discusses how the solutions to natural and man-made factors can be integrated in order to mitigate or ameliorate future building collapse in Nigeria.
\end{abstract}

Keywords: architect, building failure, geologist, Nigeria, site investigation

\section{Intorduction}

A building is a structure that serves as shelters for man and his activities in an environment (Tauheed, 2007). Building can be defined as a roofed and walled structures built for permanent use for man's living, working and storage (Encyclopaedia Britannica, 2004). In order to obtain the desired satisfaction, comfort and safety, every building whether temporary, permanent or monumental structures needs to be properly designed, well planned, constructed and maintained. According to Hornby (2001), failure is defined as non-occurrence, running short, ill success, breaking down, in solvency and unsuccessful attempt. Building collapse is a global phenomenon. Oyewande (1992) observed that building failures are attributed to the following causes: design faults $(50 \%)$, faults on construction site (40\%) and product failure (10\%). While Akinpelu (2002) categorized the following as major causes of structural failures: environmental changes, natural and man-made hazards; improper presentation and interpretation in the design. Failure could occur in the form of partial or total collapse of the structure as illustrated in Figure 1.

This paper therefore discusses an overview of the causes of building failures in Nigeria and how solutions to natural and man-made factors can be integrated in order to mitigate or ameliorate future building collapse in Nigeria.

\section{Causes of Building Failures in Nigeria}

Most of building failures in Nigeria are attributed to lack of knowledge or neglect by some of the professionals in the building industry, whereby responsibilities are not assigned to various specialised experts who are expected to pre-determine the necessary information and actions to be taken as regards to site, environment and the building to 
be constructed. Globally, the collapse of building can be attributed to two major factors namely: natural and man-made factors. They are the key factors that also generate building collapse in Nigeria.

\section{Natural Factors}

Natural factors that give rise to building collapse are subdivided into two groups: Geological phenomenon that causes building failures and geo-materials that lead to the collapse of building. The possible geological phenomenon that causes building collapse is as follows: volcanic eruption (volcanicity), subsidence, erosion and flooding, earthquake, landslide, mud-flow and debris-flow, hurricane, typhoon and tsunami, faulting, rain-storm, thunder-storm and lightening.

\subsection{Volcanicity}

Nigeria by virtue of its location is free from volcanic activity and its negative tendencies. Volcanic activities (volcanicity) embrace all the activities and processes by which gaseous liquid and solid substances of internal origin are injected into the earth crust. Basically, there are two main processes of volcanic activities which are the intrusion of masses of magma and the extrusion on the surface of molten rock material. Volcanic activity is directly related to plate tectonics and most active volcanoes are located near plate boundaries. Features that are often associated with volcanoes or volcanic areas include craters, calderas, volcanic vents, geysers and hot spring. Volcanic eruptions are of two principal types namely: linear or fissure eruption and central or vent eruption. Phases of volcanoes include active, dormant, extinct, and destructive phases. Volcanoes could be shield, composite and dome in nature.

\subsection{Subsidence}

Subsidence is one of the causes of building failures in Nigeria. This is the sinking/settling down of land resulting from natural shifts or human activity, frequently causing structural damage to buildings. Coastal areas of Southern Nigeria experience this problem becomes the soils in the area are generally weak and differential settlement usually results, leading to building failure. A devastating subsidence occured in Tyulugh Village of Nyieve Town in Kwande Local Government Area of Benue State in 2011, leading to loss of properties and farmlands.

\subsection{Erosion and Flooding}

Erosion is the scraping, scratching, grinding, and pulverizing of the earth's surface rock. Various agents of erosion which carve and shape the earth's natural surface rock includes running water, groundwater, gravity, moving ice, wind action, waves and current. Erosion can be of the following types: stream, wind, marine and glacial erosion. While the natural process of over bank flow of a river is called flooding. Most river flooding is a function of the amount and distribution of precipitation in the drainage basin, the rate at which precipitation are infiltrated into the soil. However, some floods result from rapid melting of ice, snow and dam failure. Land-use affects flooding greatly. Urbanization without adequate provision for flood channels increases both the magnitude and frequency of flooding. Floods are a function of rainfall and runoff in an area. Factors that determine the catastrophic nature (magnitude) of floods are: land-use on the floodplain, duration of flooding and sediment load. When erosion and flood effect are not considered on a site during design such building is at risk of collapsing. Hundreds of buildings and properties worth millions of naira were destroyed in Ibadan, the Oyo State Capital during last year's rainy season. Investigations showed that majority of the buildings were domiciled along floodplain without good drainage system.

\subsection{Earthquake}

This is natural shaking (vibrating) of the earth in response to the breaking of rocks along faults. Earthquakes are series of shock vibration generated at the focus, within the earth crust or mantle. The point on the surface of the earth above the focus is called the epicentre. The three main types of waves that are generated by an earthquake are: L-waves, S-waves and P-waves. Vibrations which are caused by earthquake can be dictated and recorded by an instrument called Seismometer. Earth quakes are caused by sudden movement within the earth crust or release of build-up stress and strain within the earth crust. It is interesting to note that earthquake does not occur everywhere, neither do they occur with equal intensity, rather its occurrence are concentrated along the long narrow load belt characterised by zones of crustal weakness and major fracture. African continent are very stable with little or no occurrence of earthquake unlike other continents. This is why Nigeria has not experience any building failure via earthquake as witnessed in some countries.

\subsection{Landslide}

Landslides constitute a serious natural hazard in many parts of the world, particularly in urban areas. Landslide refers to a rapid down-slope movement of soils as a coherent mass. Landslides and other ground failure are natural 
phenomena but are generally enhanced by human activity. Landslides on naturally sensitive slopes are sometimes averted by means of stabilizing structures or techniques thereby reducing the substantial damages (houses) and loss of life. It is the complex combination of sliding and flowage. Factors such as type of earth material, slope angle, climate, vegetation, water and time determines the magnitude of landslide in an area. In Nigeria for example, Anambra (Agulu and Nanka) and Benue State has recorded some buildings collapsed as a result of landslide. Most landslides in these areas are triggered by erosion.

\subsection{Mud-flows and Debris-flows}

The most serious secondary effects of volcanic activity are debris flows and mudflows. The distinction between debris flow and mudflow depends on the dominant size of the particles. In debris flow more than $50 \%$ of the particles are coarser than sand ( $2 \mathrm{~mm}$ in diameter). Debris-flow involves rapid down-slope movement of earth material often involving saturated, unconsolidated material that has become unstable because of torrential rainfall. Debris flow can travel many kilometres down valleys from the flanks of the volcano where they were produced. The copious amount of melt water produce floods which may erode and incorporate sediment such as volcanic ash and other material on the slope of the volcano, forming debris flow. While Mud-flow is a mixture of unconsolidated material and water that flows rapidly down-slope. It comprises a mixture of water, volcanic ash, rock and organic debris.

\subsection{Hurricane, Typhoons and Tsunami}

Hurricanes are tropical cyclone characterised by circulating winds of $100 \mathrm{~km} / \mathrm{hr}$ or greater generated over an area of about $160 \mathrm{~km}$ in diameter. It is known as typhoon in the ocean. Tsunamis are seismic sea waves generated by submarine volcanic activity. It is characterised by very long wave length and moves rapidly in the open sea where it is known as tidal waves. Hurricane, Typhoons and Tsunami activities are catastrophic in nature and whenever it occurs, buildings and human lives are not spared. Globally they are among the causes of building collapse.

\subsection{Faulting}

Faults are fractures in rocks with relative movement (displacement). Faults unlike joints are associated with movement along a fault plane or zone. Faulting is advantageous in areas of mineral and water exploration as well as aiding easy blasting in quarry sites while the demerits are seen in the erection of engineering structures like buildings and dams. Any building constructed along a fault zone will definitely collapse someday as the faults widen, cracks are created on the walls of the building and this will result to its collapse. In Chanchaga area of Minna in Niger State, Nigeria a major fault zone has been identified (Oke et al., 2009b). There are pronounced and noticeable cracks along the ground and at the building walls at the Leprosy Centre and IBB Specialist Hospital. Geological, geophysical and geotechnical investigations carried out in the area revealed that these cracks are prominent and penetrative (Amadi et al., 2010).

\subsection{Rain-Storm, Thunder-Storm and Lightening}

This has the potential of causing building failures. Case of building collapse in Lagos via rain-storm and thunder-storm abound. These natural disasters are accepted as "an act of God" according to Onyemachi and Uji (2005); the victims accept the calamity in good faith. Although, nobody has the power over nature, most natural disasters can be avoided (minimised) through the use of technology (disaster monitoring equipment) and environmental impact assessment (EIA).

\section{Geologically Derived Materials that Could Contribute to Building Failures}

There are some geologically derived materials that could lead to building failures, they include: Soluble rocks (limestone, chalk, gypsum etc.), clay (shrinking and swelling ability), Groundwater (shallow water table), Soil geochemistry ( $\mathrm{pH}$, sulphate and chloride), Peat and Unconsolidated recent deposits.

\subsection{Soluble Rocks (Limestone, Chalk and Gypsum)}

Sedimentary rocks like limestone, chalk and gypsum are weak, soluble and of very low bearing capacity. Erecting Building on this soluble soil are dangerous (liable to collapse) due to its low bearing capacity and high compressibility. Such weak soils should be excavated and backfilled with soil of higher bearing capacity.

\subsection{Clay (Shrinking and Swelling Ability)}

Clays are fine-textured, sedimentary that is composed of hydrated allumino-silicates. Based on grain-size, clay is any fine-grained sediment that is less than 4 microns. Clay has wide range of application, but due to its swelling ability when wet and shrinking nature when dry which has the potential of causing cracks on wall of building and tarred roads. The plasticity and low bearing capacity of clay soil makes it unfit for their use as constructional materials. The clay minerals (montmorillonite, illite and chlorite) are responsible for the swelling and shrinking 
properties in clay soils should be excavated and replaced with a much stronger soil. This a major challenge in building/construction in southern Nigeria where the soil dominantly clay and water-logged. This is necessary in order to avert failures of engineering structures like roads and buildings.

\subsection{Groundwater (Shallow Watertable)}

Groundwater is the water occupying the void spaces in rocks. It is the water stored in the zone of saturation. It may be of magma (Juvenile source), trapped within sediment (Connate Source) and from rainfall (Meteoric Source). Areas where the groundwater table is very close to the ground surface (shallow water-table), there is a tendency of the groundwater reacting with the cement portion of the foundation and this situation can weaken the entire foundation thereby causing building failures. Major towns like Lagos, Port-Harcourt and Warri have the problem of shallow watertable and seawater intrusion (Amadi et al., 2012).

\subsection{Soil Geochemistry ( $p H$, Sulphate and Chloride)}

$\mathrm{pH}$ is a measure of the acidity or alkalinity of a medium. It is simply defined as the hydrogen ion concentration and is determined with the aid of a $\mathrm{pH}$ metre. $\mathrm{pH}$ values between (0-6) indicates acidity, 7 is neutral while (8-14) shows alkalinity. Most biological and physio-chemical processes taking place in the soil are to a large extent controlled by the soil $\mathrm{pH}$. The acidity of the soil has the potential of dissolving the cement component of the foundation thereby weakening the foundation. The acidity content of the soil can be reduced by the application of lime. Similarly, excessive sulphate content in the soil has aggressive effect on the cement used in constructing the foundation of buildings. Also, much chloride content in the soil can lead to rusting (corrosion) of the metallic component of the foundation (Tomlinson, 1999; Oke \& Amadi, 2008).

\subsection{Peat}

Geologically, peat is the name given to the layer of dead vegetation in varying degrees of alteration, resulting from the accumulation of the remains of marsh vegetation in swampy hollows in cold and temperate regions. Peats are regarded as the youngest member of the series of coal of different ranks. Increase in temperature changes peat to lignite, sub-bituminous, bituminous, anthracite and graphite. Their caloric value increases with temperature. In terms of building construction, peat soils are very weak and should be excavated and back-filled with a more stable soil. Construction works whose foundation rests on peat usually collapse because it cannot withstand the load from the foundation due to its low bearing capacity. Most parts of Enugu, Kogi, Benue and Gombe States are underlain by peats, lignites or coal formations.

\subsection{Unconsolidated Recent Deposits}

These are non-cemented, highly friable materials that are newly deposited. Such materials are loose and cannot withstand the load from foundations. Building Construction on this type of soil is deceptive and should be discouraged. The recent sediments are not good constructional material due to friability. Niger Delta area of Nigeria has this problem and is part of the causes of building failures in the region (Amadi et al., 2012).

\section{Man-made Facotrs}

These are as a result of human errors before, during and after the construction of a building such as: poor design and construction, use of sub-standard and untested local materials, greedy and poor maintenance culture, foundation failure, absence of site investigation and engagement of quacks/non-professionals:

\subsection{Poor Design and Construction}

According to Uji and Onyemachi (2005), the causes of most collapsed buildings in Nigeria are traceable to poor design and wrong construction methods. Architects and Structural Engineers that find themselves at the design stages should be careful to see that necessary variables are considered at this stage such as the nature of the soil, type and sizes of materials specified. Adopted construction method applied by some contractors has also added to cases of building collapse in Nigeria. Failure of most contractors to build according to specifications and plans often results to structural anomalies in building.

\subsection{Use of Sub-standard and Untested Local Materials}

The use of sub-standard (inferior) material in building construction account for about $10 \%$ contributing factor to cases of collapse building in Nigeria (Oyewande, 1992). Poor mixing of concrete aggregate, poor quality steel reinforcement and use of sub-standard blocks from some block industries contribute their own factor to building collapse in Nigeria. Some of these constructional materials did not meet specified standard nor any quality control checks conducted on them before they are used for the construction. The frequent use of inferior and untested local building material leads to structural failures in buildings as shown below. 


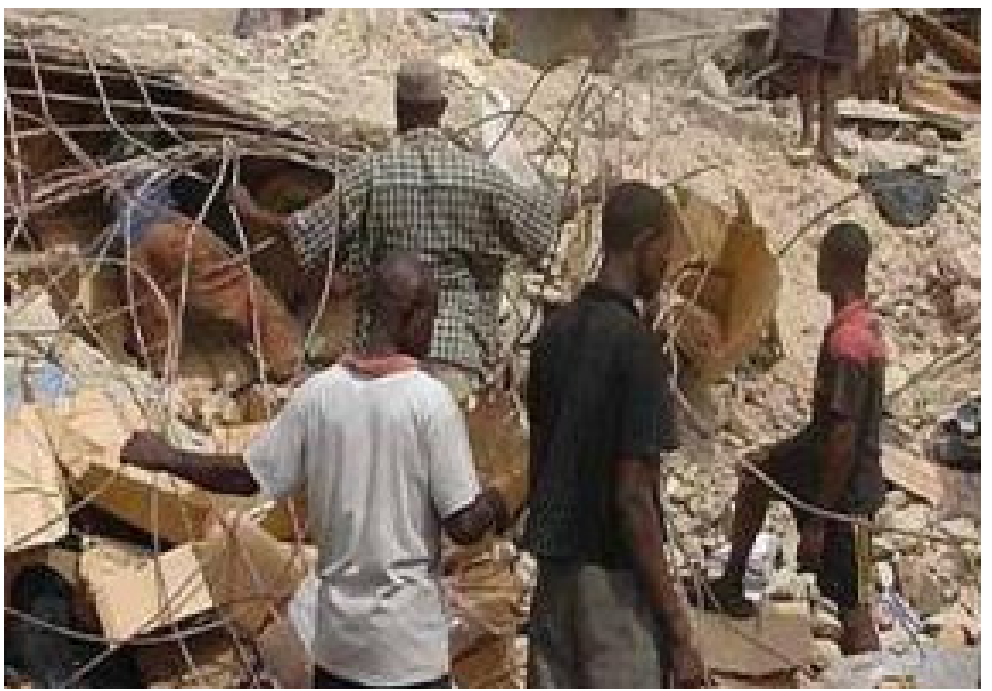

Figure 1. A collapse building due to use of sub-standard material (Source: Author, 2012)

\subsection{Greed and Poor Maintenance Culture}

Greedy or get-rich-quick syndrome in the life of most Nigerian has its negative impact on the building industry. Take for instance, the case of a building that collapsed in Lagos in 2007, a building which was originally designed for a three storey but out of greediness, the owner decided to add extra two floors. This additional weight on the structure without due consideration of the foundation, column and slab led to the collapse of the building (Oke et al., 2009a). Adequate maintenance of building is necessary for the safety and durability of the structure. Poor management and maintenance in buildings leads to development of cracks on the walls, differential settlement and premature ageing of the structure. These deficiencies when not checked could result to building failures.

\subsection{Foundation Failure}

All engineering works start with the foundation. The purpose of a foundation is to transfer the load of structure to the ground without causing the ground to respond to uneven or excessive movement. Such load must be transferred in such a way that there will be no shear failure in the underlying soils. Many buildings have collapsed due to faulty foundation (Figure 2). Most of the foundations in Nigeria are designed without considering the soil type on which they rest upon. Therefore, it is vital that adequate soil investigation should be carried out before designing of foundation in-order to have a suitable design to suit the local geology of the area.

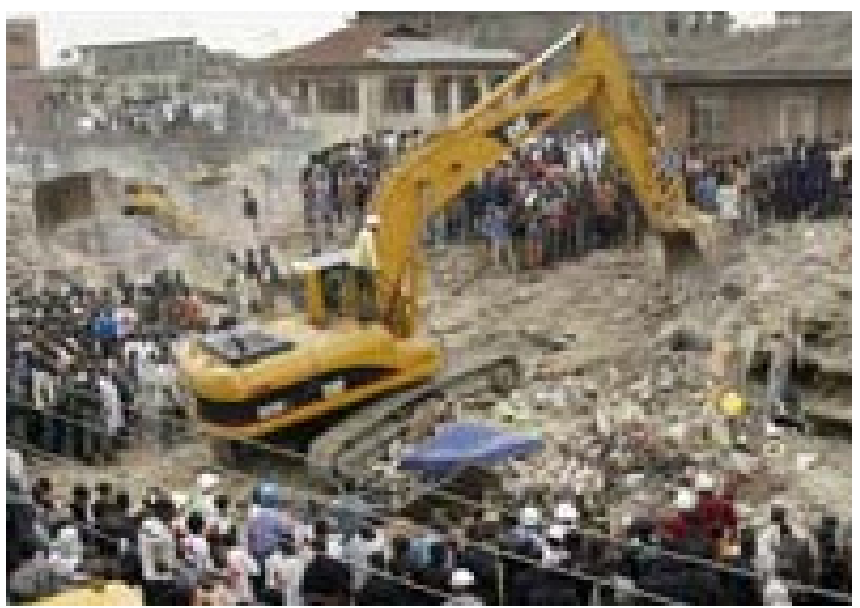

Figure 2. Collapsed building arising from foundation failure (Source: Author, 2012)

\subsection{Absence of Site Investigation}

According to Hornby (2001), investigation is defined as an examination or enquiry into something, especially a detailed one that is undertaken officially. Site investigation is therefore the act of undertaking an examination of 
site (a piece of land). This is a process whereby surveyors, geologists, architects, engineers, builders and other professionals obtain information for successful project attainment. Architect as the head of building construction team should make provision for site investigation. It is vital to the success of any construction project, because inadequate or absence of soil investigation can lead to very large construction cost over-runs. If site investigation is to be effective, it must be carried out in a systematic way using techniques that are relevant, reliable and cost effective. Lack of site investigation has always led to foundation failure which results in building failures. Site investigation helps to reveal the weak and soluble soil in the area.

\subsection{Engagement of Quacks/Non-professionals}

A number of professionals (stakeholders) exist in the building industry, but in most cases their services are not sought for due to one reason or the other, such professionals include: Architects, Quantity Surveyors, Land Surveyors, Builders/Contractors, Engineers (Structural, Civil, Mechanical, Electrical, and Geotechnical). It has been observed that due to high cost of consultancy fees needed to engage the services of these professionals, most Nigerians prefer to cut cost by engaging the services of non professionals (quacks) who lack the needed experience in construction sector. This is reflected in poor workmanship and low standard of construction, which results in structural failure and collapse of part or the entire building. Take for instance, the recent loss of human lives in the collapse of two storey building located at road $45,1^{\text {st }}$ Avenue Gwarinpa, Abuja on the $28^{\text {th }}$ of January, 2012; according to 'Sunday Sun Newspaper' of January 29, 2012 on page 11; the collapse was as a result of involving non-professionals in the demolition of the said building for further renovation which led to collapse of the structure (Figure 3).

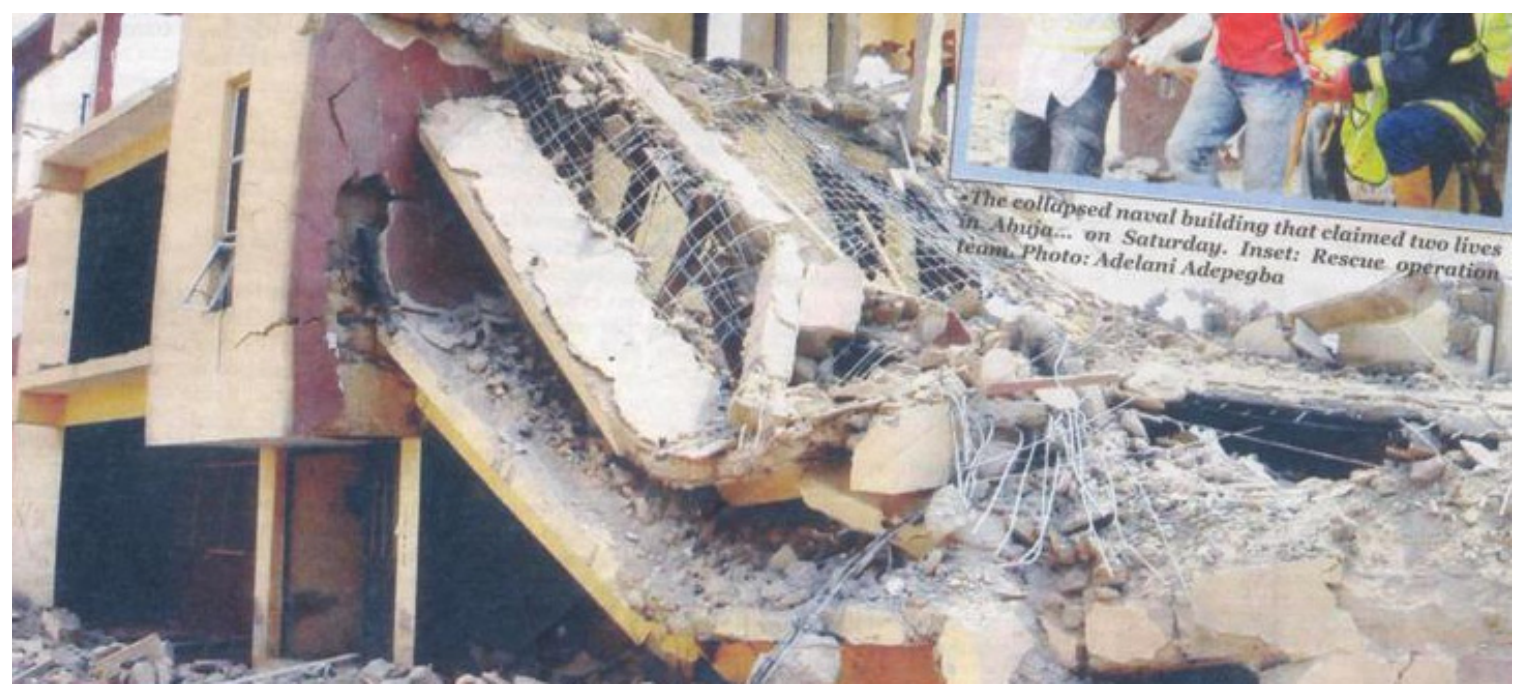

Figure 3: Building collapse as result of engagement of quacks/non-professionals (Source: Sunday Sun Newspaper' of January 29, 2012)

\section{Economic and Health Impacts}

The economic and health implication associated with collapsed building are:

(i) Loss of lives and properties.

(ii) Psychological trauma for survivors.

(iii) Economic waste (cost of removal of rubbish and financial assistance for the victims).

(iv) Environmental pollution via dust, noise and leakage from bust pipes.

(v) Waste of resources and time through re-building exercise.

\subsection{Case Studies}

Detailed site investigation of a four storey residential building covering $420 \mathrm{~m}^{2}$ at No.56 Bola Street, Ebute-Metta, Lagos; that collapsed on the $26^{\text {th }}$ of July, 2006 revealed the existence of reddish brown silty-clay material and compressible waste material like wood, plastic and nylon occurring from ground surface to about $11 \mathrm{~m}$ on which a shallow strip foundation was used (Oke et al., 2009). Similarly, on July $1^{\text {st }}, 2006$, a three storey building collapsed along Bank Road, Port Harcourt. The subsoil conditions in the two sites were investigated using a percussion rig and an auger tool was used to bore to $25 \mathrm{~m}$ below ground level according to British Standard Code of Practice for 
site investigation. Disturbed and undisturbed soil samples were collected from the borehole and taken to the laboratory for relevant geotechnical analyses. Dry sieve analysis was carried out in order to obtain the particle size distribution of the soil samples. The results of the geotechnical survey conducted on the two sites show some similarity in their geotechnical properties. The liquid limit varies from $27.0 \%$ to $28.8 \%$, the plastic limit ranges from $15.0 \%$ to $21.0 \%$, the plasticity index is of the order of $6.0 \%$ to $13.5 \%$ while shrinkage potential ranges low to medium. The triaxial stress ranges from 0.0 to 336.5 , the coefficient of consolidation varies from $2.73 \mathrm{~m} / \mathrm{yr}$ to 58.2 $\mathrm{m} / \mathrm{yr}$, the bulk density ranges from $1.60 \mathrm{mg} / \mathrm{m}$ to $2.12 \mathrm{mg} / \mathrm{m}$ while the moisture content varies from $14.36 \%$ to $22.20 \%$. The study reveals the presence of weak soil (clay) and highly compressible material (peat) of $11.0 \mathrm{~m}$ from the existing ground level on which a shallow foundation was erected. The excavations on the sites shows the presence of wood, nylon, plastic materials and silty clay, which suggested that the sites were used previously as dumpsites (Oke \& Amadi, 2008). A pre-construction geotechnical investigation would have reviewed the unfavourable condition of the sites and the subsequent improvement on the respective soil bearing capacity could have prevented the buildings from collapsing.

\section{Recommendations}

(a) A pre-constructional geotechnical survey or soil survey should be carried out before the commencement of any design and or construction especially in low lying terrain susceptible to high ground water table fluctuation and compressible soil.

(b) Engagement of Professionals from design stage to completion stage should be made mandatory in the construction of future building.

(c) Various regulatory bodies such as Council of Registered Engineers (COREN), Council of Nigerian Mining Engineers and Geoscientist (COMEG), Architects Registration Council of Nigeria ARCON and Council of Registered Builders of Nigeria (CORBON), should ensure that only registered and qualified professionals are involved in the construction of future buildings in order to minimize failures.

(d) The National Building Code enacted for Nigeria should be enforced throughout the country by the necessary authorities and future construction of building should comply with the building codes.

(e) Standard Organization of Nigeria (SON) and other relevant agencies should ensure that all constructional materials like blocks, cement, reinforcement steel are tested and standards not compromised.

(f) The Federal, State and Local Governments should prosecute offender(s) who carryout building construction without complying with the Code or use poor constructional material for the building.

(g) Nigerian should have a change of attitude in terms of get-rich-quick and poor maintenance culture by not compromising standards and reflecting on the loss of lives and properties involved in any building collapse.

(h) All the professionals in the building industries should work as a team and in harmony as these will go a long way in restoring sanity in the construction sector.

\section{Conclusion}

Collapse of building is a global phenomenon and is always associated with loss of lives and properties. Nigeria by virtue of its location in the globe is rarely affected by the natural factors except very few cases attributed to erosion and flooding as well as rainstorm and thunderstorm in the northern and southern part of the country respectively. The major reasons why building collapse in Nigeria are traceable to man-made factors which includes: Absence of site investigation by Geotechnical Engineer or Geologist before construction, Poor Design, Foundation Failures, Improper Construction, Use of Sub-standard Construction Material Engagement of Non-professional, Greedy and Poor Maintenance. The identified causes of building failures should be addressed squarely by all the stakeholders in the sectors.

\section{References}

Akinpelu, J. A. (2002). The need for code of conduct, building regulations and bye-laws for industry in Nigeria. The Professional - Builder, Nigeria Institute of Building, pp. 11-14.

Amadi, A. N., Olasehinde, P. I., Okunlola, I. A., Okoye, N. O., \& Waziri, S. (2010). A multidisciplinary approach to subsurface characterization in Northwest of Minna, Niger State, Nigeria. Bayero Journal of Physics and Mathematical Sciences, 3(1), 74-83.

Amadi, A. N., Nwankwoala, H. O., Olasehinde, P. I., Okoye, N. O., Okunlola, I. A., \& Alkali, Y. B. (2012). Investigation of aquifer quality in Bonny Island, Eastern Niger Delta, Nigeria using geophysical and geochemical techniques. Journal of Emerging Trends in Engineering and Apllied Sciences, 3(1), 180-184. 
Encyclopaedia Britannica. (2004). Deluxe edition.

Hornby, A. S. (2001). Oxford advanced learner's dictionary of current English. Oxford: Oxford University Press.

Oke, S. A., \& Amadi, A. N. (2008). An assessment of the geotechnical properties of the subsoil of parts of Federal University of Technology, Minna, Gidan -Kwano Campus, for foundation design and construction. Journal of Science, Education and Technology, 1(2), 87-102.

Oke, S. A., Amadi, A. N., Abalaka, A. E., \& Akerele, R. T. (2009a). Result of subsoil investigation on a collapsed building site in Lagos. Nigerian Journal of Construction Technology and Management, 10(1\&2), 36-45.

Oke, S. A., Okeke, O. E., Amadi, A. N., \& Onoduku, U. S. (2009b). Geotechnical Properties of the Subsoil for Designing Shallow Foundation in some selected parts of Chanchaga area, Minna, Nigeria. Journal of Environmental Science, 1(1), 45-54.

Onyemachi, T. U., \& Uji, Z. A., (2005). Building failures and it's implication on real estate investment in Nigeria. AARCHES Journal, 4(1), 57-63.

Oyewande, B. (2002). A research for quality in the construction industry (June- July ed.). In Builder's Magazine, Lagos.

Tauheed, I. A. (2007). Curbing the collapse of buildings in Nigeria: An issue for individual and building professionals. $1^{\text {st }}$ Annual National Conference, School of Environmental Technology FUT Minna, $28^{\text {th }}-2^{\text {nd }}$ March, pp. 37-39.

Tomlinson, M. J. (1999). Foundation design and construction. Pitman Pu. 